\title{
Vulnerabilidade e bioética: discussões sobre o filme Um homem entre gigantes
}

\author{
Luciana Teixeira Waltrick ${ }^{1}$, Francine Stein ${ }^{1}$, Alcyane Marinho ${ }^{1}$
}

1. Universidade do Estado de Santa Catarina, Florianópolis/SC, Brasil.

\begin{abstract}
Resumo
Este artigo tem como objetivo identificar percepções de estudantes de educação física sobre vulnerabilidades, intolerância e relações de poder no esporte a partir do filme Um homem entre gigantes. Trata-se de estudo descritivo-exploratório, com abordagem qualitativa. Dez estudantes de graduação e pós-graduação da Universidade do Estado de Santa Catarina responderam ao questionário on-line sobre o filme. Os dados coletados foram examinados por meio da técnica de análise de conteúdo. A obra escolhida, com temática relacionada ao esporte, mostrou-se eficiente para o ensino de temas da bioética, como tipos de vulnerabilidade, relações de poder e conflitos éticos que podem surgir na atuação dos profissionais da área de educação física. O método de ensino-aprendizagem motivou os alunos a refletir sobre temas polêmicos e situações apresentadas no filme.
\end{abstract}

Palavras-chave: Bioética. Esportes. Vulnerabilidade em saúde. Educação superior. Filmes cinematográficos.

\section{Resumen}

\section{Vulnerabilidad y bioética: discusiones sobre la película La verdad duele}

Este artículo tiene como objetivo identificar las percepciones de estudiantes de educación física sobre las vulnerabilidades, la intolerancia y las relaciones de poder en el deporte a partir de la película La verdad duele. Se trata de un estudio descriptivo-exploratorio, con enfoque cualitativo. Diez estudiantes de pregrado y posgrado de la Universidade do Estado de Santa Catarina respondieron el cuestionario en línea sobre la película. Los datos recopilados se examinaron mediante la técnica de análisis de contenido. La película elegida, con una temática relacionada con el deporte, demostró ser eficaz para la enseñanza de temas de bioética como tipos de vulnerabilidad, relaciones de poder y conflictos éticos que pueden surgir en el desempeño de los profesionales de la educación física. El método de enseñanza-aprendizaje motivó a los estudiantes a reflexionar sobre temas y situaciones controvertidas que se presentan en la película.

Palabras clave: Bioética. Deportes. Vulnerabilidad en salud. Educación superior. Películas cinematográficas.

\section{Abstract \\ Vulnerability and bioethics: discussions about the movie Concussion}

This article aims to identify the perception of physical education students on vulnerabilities, intolerance and power relations in sports based on the motion picture Concussion. This is a descriptive, exploratory study with a qualitative approach. Ten undergraduate and graduate students from Universidade do Estado de Santa Catarina answered an online questionnaire about the movie. Data was examined by content analysis. With a sports-related thematic, the selected movie proved effective for teaching bioethical topics such as types of vulnerability, power relations and ethical conflicts, which may arise from professional practice in the field of physical education. The teaching-learning method motivated students to reflect on the controversial topics and situations presented in the movie.

Keywords: Bioethics. Sports. Health vulnerability. Education, higher. Motion pictures. 
A bioética é campo de debate multiprofissional dedicado à reflexão sobre conflitos éticos e morais do mundo atual, globalizado e tecnológico. Relaciona conceitos de diferentes áreas, o que torna essencial a análise crítica e autônoma ${ }^{1}$. 0 diálogo efetivo entre as diversas áreas demonstra a importância da interdisciplinaridade, que enriquece a formação dos alunos, ajudando-os a tomar decisões ao enfrentar conflitos. A bioética já esteve muito restrita à área médica ${ }^{2}$, mas atualmente a perspectiva interdisciplinar permite criar espaços comuns de reflexão entre profissionais e, assim, proporcionar diálogos plurais ${ }^{1}$.

Como estudos atuais ressaltam, a bioética exige modelo de ensino que ofereça conhecimento e desenvolva a capacidade crítica dos alunos, habilitando-os a discutir, responder, pensar, questionar as próprias opiniões e se posicionar diante de conflitos inerentes à profissão ${ }^{3,4}$. A análise estruturada de um filme, seguida de discussão, pode facilitar esse processo, principalmente por problematizar a realidade e ancorar a reflexão e os argumentos. O cinema torna-se então ferramenta educacional importante, pois as narrativas oferecem oportunidades para pensar a complexidade humana e suas implicações na prática profissional ${ }^{5}$.

O ser humano é considerado sempre vulnerável, embora possa estar ou não em estado de vulneração ${ }^{6}$. Trata-se de condição latente que pode se tornar manifesta, uma possibilidade que pode se concretizar a depender das circunstâncias, e todas essas situações envolvem a bioética ${ }^{6}$. O termo "vulneração" se refere a contexto concreto de vulnerabilidade, determinado pelo pertencimento a uma classe social, etnia ou gênero. A "vulnerabilidade", por sua vez, aplica-se a qualquer ser humano, que pode ser ferido, mas não necessariamente o será?.

Há três tipos de vulnerabilidade: existencial, social e moral. As situações de vulnerabilidade existencial são marcadas por sofrimento, doença e morte, e atingem a todos independentemente das condições sociais. A vulnerabilidade social, por sua vez, está associada a estruturas políticas e econômicas desiguais e diz respeito a diversas injustiças cuja superação não depende apenas da boa vontade individual. Por fim, a vulnerabilidade moral surge da cultura (religião, costumes, arte) e da percepção de valores, e por isso é mais difícil de ser percebida. Os considerados moralmente vulneráveis, por serem diferentes, sofrem com discriminação, indiferença e até mesmo ódio, e a superação desse estado não depende apenas dos sujeitos atingidos, mas de transformações culturais ${ }^{8}$.

Este artigo trata especificamente da vulnerabilidade no esporte e, para isso, parte do longa-metragem Um homem entre gigantes ${ }^{9}$ como objeto de reflexão, visando debater conflitos bioéticos como as relações de poder no esporte, a vulnerabilidade do atleta e o papel do profissional de educação física. O objetivo do estudo é, por meio do filme, identificar as percepções de estudantes de educação física sobre vulnerabilidade, intolerância e relações de poder.

\section{Método}

Trata-se de estudo descritivo-exploratório com abordagem qualitativa ${ }^{10}$, do qual participaram dez estudantes de graduação e pós-graduação do Centro de Ciências da Saúde e do Esporte da Universidade do Estado de Santa Catarina, escolhidos por conveniência. O Centro foi escolhido como cenário de pesquisa pela proximidade entre o escopo de sua atuação e o tema do filme analisado.

Os estudantes aceitaram participar voluntariamente da pesquisa e assinaram termo de consentimento livre e esclarecido, bem como termo de consentimento para uso de fotos, vídeos e gravações. Todos foram previamente informados sobre o teor da investigação. A identidade dos participantes foi preservada com nomes fictícios, escolhidos pelos próprios estudantes. Os dados dos integrantes da amostra, com respectivos codinomes, são apresentados no Quadro 1. O Quadro 2 descreve as etapas da coleta de dados.

Antes da projeção de Um homem entre gigantes ${ }^{9}$, os participantes assistiram a documentário de curta-metragem ${ }^{11}$ e leram um artigo científico ${ }^{12} \mathrm{e}$ uma reportagem jornalística ${ }^{13}$ relacionados ao tema do filme. O material foi enviado aos alunos por e-mail uma semana antes da data marcada para a exibição do longa. Após a sessão, as pesquisadoras conduziram debate com duração de uma hora e meia, seguindo roteiro com perguntas sistematizadas: 1) Existem relações de poder no filme? Quais? Como elas se manifestam?; 2) Racismo ou intolerância podem ser notados no filme? Se sim, em quais momentos e de que modo?; 
e 3) Quais são os fatores de risco e as doenças ocupacionais dos atletas? Como tais enfermidades podem ser prevenidas e tratadas?

Quadro 1. Identificação dos participantes do estudo

\begin{tabular}{|c|c|c|}
\hline $\begin{array}{l}\text { Nome } \\
\text { fictício }\end{array}$ & Curso & $\begin{array}{c}\text { Idade } \\
\text { (em anos) }\end{array}$ \\
\hline Marta & Educação física, licenciatura & 23 \\
\hline Luíza & Educação física, licenciatura & 20 \\
\hline Juliana & $\begin{array}{l}\text { Mestrado em ciências do } \\
\text { movimento humano }\end{array}$ & 23 \\
\hline Nina & $\begin{array}{l}\text { Mestrado em ciências do } \\
\text { movimento humano }\end{array}$ & 24 \\
\hline Maria Izabel & $\begin{array}{l}\text { Mestrado em ciências do } \\
\text { movimento humano }\end{array}$ & 30 \\
\hline Flor & $\begin{array}{l}\text { Mestrado em ciências do } \\
\text { movimento humano }\end{array}$ & 35 \\
\hline Joana & Educação física, bacharelado & 24 \\
\hline Kaio & Educação física, licenciatura & 22 \\
\hline Rosa & Educação física, licenciatura & 21 \\
\hline Clarice & Educação física, bacharelado & 21 \\
\hline
\end{tabular}

Quadro 2. Etapas da coleta de dados

\begin{tabular}{ll} 
Etapa & \multicolumn{1}{c}{ Descrição } \\
$1^{\text {a }}$ & $\begin{array}{l}\text { Envio prévio aos alunos de referencial } \\
\text { teórico e material de apoio relacionados ao } \\
\text { tema do filme. }\end{array}$ \\
& $\begin{array}{l}\text { Projeção do filme Um homem entre gigantes } \\
\text { no auditório do Centro de Ciências da Saúde } \\
2^{\text {a }}\end{array}$ \\
$3^{\text {a }}$ & $\begin{array}{l}\text { Debate, com duração de } 1 \mathrm{~h} 30 \mathrm{~m}, \text { guiado por } \\
\text { roteiro específico. }\end{array}$ \\
& $\begin{array}{l}\text { Envio de questionário on-line contendo } \\
\text { sete perguntas. }\end{array}$
\end{tabular}

Após o debate, os participantes foram convidados a responder questionário on-line com sete tópicos (Quadro 3). O link de acesso ao instrumento foi enviado por e-mail, e o prazo para preenchimento foi de 24 horas, com vistas a captar reflexões e percepções ainda recentes.

Os dados coletados foram armazenados em planilha do software Microsoft Excel e examinados pelas pesquisadoras por meio da técnica de análise de conteúdo, composta por três etapas: pré-análise; exploração; e tratamento/interpretação dos resultados ${ }^{14}$. A pré-análise visa organizar o material e formular hipóteses. A exploração busca detectar, no discurso dos participantes, significados e ideias repetidas ou que, por algum motivo, não aparecem. Nessa fase, as unidades de registro são palavras, frases ou temas reiterados ao longo do texto ${ }^{14,15}$. Por fim, na última etapa, os resultados são analisados por meio de inferência e interpretação. Essa fase é fundamental, pois contempla a categorização, que relaciona e organiza as informações fornecidas pelas fontes de observação. Ainda nessa etapa, os resultados devem ser confrontados com a literatura e submetidos à análise do pesquisador ${ }^{14,15}$.

Quadro 3. Tópicos do questionário on-line utilizado na coleta de dados

Tópicos
1. Qual é o contexto social do filme?
2. Identifique os tipos de relação de poder presentes
no filme.

3. Quais personagens do filme podem ser considerados vulneráveis? Por quê?

4. Há intolerância no filme?

5. Por parte de quem e de que forma a intolerância se manifesta?

6. Reflita sobre as doenças ocupacionais de atletas e/ou riscos de determinadas doenças devido ao excesso de prática esportiva.

7. Discuta sobre o papel do profissional de educação física em contextos similares ao apresentado no filme.

\section{Resultados e discussão}

Todo ser humano é vulnerável ao sofrimento, à doença e à morte, mas, devido a circunstâncias específicas, como discriminação e exclusão, essa vulnerabilidade pode se transformar em vulneração. Como explica Schramm ${ }^{7}$, a vulnerabilidade é uma possibilidade; a vulneração é situação concreta relacionada a classe social, etnia, gênero ou condições específicas de saúde. No esporte, a vulnerabilidade é caracterizada por relações de poder, isto é, alguém está vulnerável a algo ou a alguém ${ }^{12}$. 
O desafio da bioética é identificar como cada pessoa é afetada pela vulnerabilidade. A vida na sociedade contemporânea exige que as pessoas provem sua utilidade ou adesão ao modelo predominante por meio de certos atributos pessoais, e esta situação acarreta relações de poder ${ }^{8}$. No meio esportivo, o termo "vulnerabilidade" é pouco utilizado, mas uma análise atenta encontra diversos fatores e cenários em que essa condição se apresenta: excesso de treinamento, lesões, doping, abandono e transição de carreira, assédio moral e/ou sexual, corrupção, racismo, discriminação de gênero, abuso emocional, culto à imagem corporal e hiperexposição nas mídias sociais ${ }^{12}$.

Rebustini e Machado ${ }^{12}$ propõem modelo hierárquico de vulnerabilidade no esporte com cinco classes. Na primeira, "instituições e políticas", técnicos e atletas têm pouca influência, e uma das categorias associadas é a corrupção. A segunda classe, "comunicação e marketing" é composta por quatro categorias diretamente relacionadas ao esporte de alto rendimento mídia, novas mídias, redes sociais e patrocínios -, e são elas que potencializam o mercado das empresas esportivas. A terceira classe, "desenvolvimento esportivo", inclui, dentre outras categorias, a do abandono esportivo, frequentemente motivado por lesões causadas por excesso de treinamento.

A quarta classe, "fatores psicossociais", engloba o dia a dia do universo esportivo, considerando gênero, religião, imagem corporal, racismo, violência, fatores emocionais e aspectos morais e éticos. Sobre esse tema, os autores salientam que os corpos no esporte são veículos primários não apenas para o desempenho, mas também para a imagem, (...) que vai estampar (...) diversos produ$\operatorname{tos}^{16}$. Por fim, a quinta classe, "desempenho esportivo", abarca resultados, excesso de treinamento, doping, lesões e expatriação. Acerca dessa classe, uma frase dos autores chama atenção: todo o (...) investimento no atleta é voltado a um único objetivo final: o resultado ${ }^{17}$.

$O$ assédio foi considerado categoria transversal, pois perpassa todo o cenário esportivo. Essa agressão pode ser sexual ou moral e perpetrada por torcedores, jornalistas, agentes e empresários. Também a família do atleta pode ser vítima ou perpetradora de assédio, e um dos pontos de vulnerabilidade do esportista é justamente ser muitas vezes colocado como a solução dos problemas familiares ${ }^{12}$.

Com relação ao contexto social apresentado em Um homem entre gigantes ${ }^{9}$, seis participantes descreveram a vulnerabilidade relacionada a imigração e racismo. Como exemplo, Maria Izabel aponta que o filme apresenta diferentes formas de intolerância, como racismo e xenofobia (por parte do médico americano em relação ao médico africano); intolerância racial (menosprezavam o médico por ser negro); intolerância aos estrangeiros (o médico era subjugado e queriam que ele fosse embora); intolerância religiosa (por parte do pesquisador ao desmerecer a crença do médico).

Quanto às relações de poder, Juliana e Flor ainda ressaltaram:

"É nítida a hierarquização. A National Football League [NFL] está no topo e controla as pesquisas, as notícias e até mesmo o FBI. Todos de certa forma são coagidos pelo poder da liga" (Juliana).

"A principal relação de poder diz respeito à NFL e ao médico, o qual se sente impotente diante da descoberta de uma doença capaz de matar os jogadores da liga" (Flor).

Oito participantes identificaram as seguintes relações de poder: entre os legistas do laboratório; entre os médicos pesquisadores; e entre o médico-legista Omalu (o protagonista) e os médicos da NFL. Rosa identificou a relação de poder na fala "só é verdade se eles disserem que $e ́$ ", proferida no filme durante conversa entre o médico-legista, o antigo médico do time da cidade e o médico da NFL.

A vulneração pode ser identificada no filme, por exemplo, quando Omalu, mesmo pertencendo a classe socioeconômica privilegiada, encontra dificuldades concretas no ambiente de trabalho em razão de sua etnia. Depois de descobrir a patologia que acomete jogadores, o médico continua neste estado de vulneração, visto que sua manifestação contraria os interesses das "instituições e políticas", sobre as quais técnicos e atletas têm também pouca influência ${ }^{12}$.

De acordo com o artigo 11 da Declaração Universal sobre Bioética e Direitos Humanos ${ }^{18}$, discriminar ou estigmatizar alguém, por qualquer razão, viola a dignidade, os direitos e as liberdades 
fundamentais da pessoa. O estigma e a discriminação contrariam o reconhecimento da alteridade e negam a tolerância, entendida como respeito pela diferença. Goffman ${ }^{19}$ discute o estigma como atributo depreciativo, que vê diferenças como desvios e desacredita aqueles que as apresentam. Godoi e Garrafa ${ }^{20}$, por sua vez, destacam que a discriminação é parte inerente do estigma, de modo que não há estigma se não houver discriminação.

Ainda conforme Godoi e Garrafa ${ }^{20}$, mesmo que a discriminação seja experiência individual, que ocorre nas relações entre pessoas, as condições para que grupos economicamente dominantes imponham sua visão de mundo, seus valores e suas normas em detrimento de grupos minoritários ou em desvantagem social são criadas pelas estruturas sociais. No filme, pode-se perceber o abuso cometido contra pessoas em desvantagem, seja esta socioeconômica, política ou étnica. Nesta perspectiva, fica claro como os atletas, o técnico e o médico do time se encontram em estado de vulneração ${ }^{12}$.

Kottow ${ }^{21}$ apresenta dois tipos de vulnerabilidade: a intrínseca, própria da existência humana; e a circunstancial, que afeta seres humanos por meio da pobreza, da discriminação, de doenças evitáveis e da falta de acesso à educação e à saúde. Segundo o autor, indivíduos vulneráveis devem ser protegidos, uma vez que precisam de assistência para enfrentar a causa de sua fragilidade e ter supridas suas necessidades não atendidas, que os predispõem a sofrer danos ${ }^{21}$. Todos os estudantes perceberam no filme a vulnerabilidade intrínseca do ser humano, como se verifica em algumas falas:

"Todos os personagens do filme podem ser considerados vulneráveis. Ao entender a vulnerabilidade como característica comum a todos, percebe-se que cada um demonstra ser vulnerável em relação a determinada situação" (Joana).

"Os atletas podem ser considerados vulneráveis por não saberem a que estão expostos, à doença potencialmente capaz de matá-los" (Flor).

Com as concussões provocadas no jogo e o uso excessivo de medicamentos - situações que colocam os atletas em estado de vulneração -, é possível identificar no filme a categoria do modelo hierárquico de vulnerabilidade de Rebustini e Machado ${ }^{12}$ que envolve resultados esportivos. Com o passar dos anos, a busca excessiva por aumentar o desempenho e alcançar tais resultados pode levar ao abandono do esporte por doença ocupacional ${ }^{12}$.

Avanços industriais, científicos e tecnológicos têm criado agentes farmacológicos e modelos de treinamento mais sofisticados para desenvolver aptidão física, força muscular e habilidades atléticas ${ }^{22}$. No entanto, substâncias e métodos capazes de aumentar o desempenho esportivo artificialmente são prejudiciais à saúde dos atletas e contrários ao espírito do jogo ${ }^{22}$. Corroborando essa ideia, ao refletir sobre riscos e doenças ocupacionais por excesso de prática esportiva, Marta, uma das participantes do estudo, destaca que "muitas doenças permanecem camufladas por trás de toda política, finanças e marketing envolvidos nos esportes".

Conforme Silva ${ }^{23}$, em um mundo em que se valoriza excessivamente o corpo e o capital, diversos abusos ocorrem na busca por rentabilidade e poder. Nesse contexto, desde cedo - pois ingressam no esporte ainda em fase escolar - os atletas estão vulneráveis a imposições de terceiros, sem poder gozar de sua autonomia. Além disso, a vida profissional desses atletas é curta, devido ao desgaste precoce do corpo. A maturidade profissional é atingida ainda na juventude, quando se pode aproveitar ao máximo a potencialidade do corpo para buscar resultados ${ }^{23}$.

Uma das participantes do estudo, Luíza, lembra que muitos atletas "não conseguem se reinserir no mercado de trabalho após a aposentadoria ou o abandono da carreira devido a lesões, estresse ou [perda do interesse] por ter iniciado a carreira precocemente". Clarice, por sua vez, destaca que "o esporte de alto nível foge consideravelmente do quesito saúde. Dores, lesões, contusões, traumas psicológicos fazem parte do dia a dia dos atletas". Juliana resume o problema:

"Acredita-se no esporte como sinônimo de saúde; no entanto, o esporte de alto rendimento pode ser extremamente prejudicial à qualidade de vida do atleta. O nível de comprometimento pode fazer com que as lesões e dores sejam entendidas como normais. Assim, inicia-se um processo perigoso de entrega, no qual os cuidados à saúde são negligenciados. Portanto, o excesso da prática pode acarretar doenças, por meio de treinamentos agressivos e objetivos exagerados em que o atleta abre mão da saúde, muitas vezes sem saber das consequências". 
Os avanços tecnológicos na medicina esportiva e a criação de técnicas invasivas e não invasivas para melhorar o desempenho têm suscitado conflitos e debates éticos sobre limites e implicações para a saúde do esportista ${ }^{23}$. Os trabalhadores da área de educação física podem e devem contribuir com essas discussões, seja produzindo conhecimento sobre o assunto, seja por meio da própria atuação profissional. No entanto, para isso é preciso considerar os aspectos biopsicossociais do movimento humano ${ }^{24}$.

Discutindo o papel do profissional de educação física em contextos similares ao apresentado no filme, Nina denuncia que "muitos dos profissionais de educação física são coniventes e aceitam as condições propostas em prol de fama, destaque, sucesso e lucro. A partir disso, percebe-se a importância de profissionais com uma formação mais sensivel e humanizada, os quais poderiam agir de forma diferente, atuando na troca de informações preventivas e de cuidado - informações estas que seriam sementes para futuras melhorias na condição física e psicológica dos jogadores".

Kaio complementa essas ideias afirmando que "um profissional que preza pela ética e pela moral está extremamente vulnerável nesse contexto, pois a única opção que resta é ir contra esse sistema, o que, como podemos observar no filme, não é nada fácil". Nas falas, percebe-se a importância da reflexão ética acerca da conduta profissional.

Nesse sentido, é papel da bioética tentar impedir que avanços científicos e tecnológicos estejam a serviço de práticas estigmatizantes e discriminatórias que reforçam o poder de grupos sociais dominantes. Esse campo do conhecimento desenvolve suas reflexões justamente porque os vulneráveis estão sujeitos à ação dos mais fortes, que podem causar danos por meio de desatenção, negligência ou malícia, explorando os mais fracos ${ }^{18}$.

Como constata Benatar ${ }^{25}$, a bioética foi capaz de reformular o equilíbrio de poder na relação médico-paciente, e isso já é motivo para estimular esse campo do conhecimento no século XXI. No Brasil, ainda são necessárias pesquisas que relacionem a bioética a outras ciências da saúde ${ }^{2}$. $\mathrm{Na}$ área da educação física, como afirma Santin ${ }^{26} \mathrm{e}$ como mostra o estudo de Rebustini e Machado ${ }^{12}$, essa aproximação é particularmente importante, dada a vulnerabilidade dos atletas e demais pessoas envolvidas. Assim, o estudo da bioética no ensino superior deve ser estimulado para além da área médica, para que mais agentes possam intermediar conflitos surgidos com o avanço da tecnologia, de modo que o equilíbrio de poder trazido para a relação médico-paciente se estenda a outras relações.

\section{Considerações finais}

A discussão de questões bioéticas a partir do cinema é relevante no contexto acadêmico, pois permite trabalhar dilemas comuns na vida de profissionais da saúde, produzindo conhecimento na área e estimulando diálogo entre pessoas com diferentes visões. Filmes são capazes de provocar sentimentos e mudar o olhar das pessoas ao conectá-las com suas próprias reflexões.

Neste estudo, o filme Um homem entre gigantes ${ }^{9}$ mostrou ser recurso eficiente para incitar a reflexão sobre temas da bioética entre alunos da área da educação física. O longa-metragem apresentou relações de poder, vulnerabilidades e condutas profissionais relacionadas ao esporte. A análise estruturada da obra e o debate em conjunto, com apoio de material previamente apresentado aos estudantes, fizeram com que a abordagem dos temas fosse mais estimulante. Os participantes puderam refletir sobre suas próprias condutas e se tornar mais conscientes da importância de visão mais aprofundada sobre conflitos bioéticos no esporte.

\section{Referências}

1. Schwartzman UP, Martins VCS, Ferreira LS, Garrafa V. Interdisciplinaridade: referencial indispensável ao processo de ensino-aprendizagem da bioética. Rev. bioét. (Impr.) [Internet]. 2017 [acesso $1^{\circ}$ jul 2020];25(3):536-43. DOI: 10.1590/1983-80422017253210

2. Figueiredo AM, Garrafa V, Portillo JAC. Ensino da bioética na área das ciências da saúde no Brasil: estudo de revisão sistemática. Interthesis [Internet]. 2008 [acesso $1^{\circ}$ jul 2020];5(2):47-72. DOI: $10.5007 / 1807-1384.2008 v 5 n 2 p 47$ 
3. Maluf F. Formação em bioética: uma análise de cursos de pós-graduação lato sensu no Brasil [tese] [Internet]. Brasília: Universidade de Brasília; 2015 [acesso $1^{\circ}$ jul 2020]. Disponível: https://bit.ly/3t8hBsw

4. Andrade AFL, Pessalacia JDR, Daniel JC, Euflauzino I. Processo ensino-aprendizagem em bioética: um debate interdisciplinar. Rev Bras Educ Méd [Internet]. 2016 [acesso $1^{\circ}$ jul 2020];40(1):102-8. DOI: 10.1590/1981-52712015v40n1e01732015

5. Dantas AA, Martins $\mathrm{CH}$, Militão MSR. O cinema como instrumento didático para a abordagem de problemas bioéticos: uma reflexão sobre a eutanásia. Rev Bras Educ Méd [Internet]. 2011 [acesso $1^{\circ}$ jul 2020];35(1):69-76. DOI: 10.1590/S0100-55022011000100010

6. Hossne WS. Dos referenciais da bioética: a vulnerabilidade. Bioethikos [Internet]. 2009 [acesso $1^{\circ}$ jul 2020];3(1):41-51. Disponível: https://bit.ly/36j4Kd9

7. Schramm FR. A saúde é um direito ou um dever? Autocrítica da saúde pública. Rev Bras Bioét [Internet]. 2006 [acesso $1^{\circ}$ jul 2020];2(2):187-200. Disponível: https://bit.ly/36j4UkL

8. Sanches MA, Mannes M, Cunha TR. Vulnerabilidade moral: leitura das exclusões no contexto da bioética. Rev. bioét. (Impr.) [Internet]. 2018 [acesso $1^{\circ}$ jul 2020];26(1):39-46. DOI: 10.1590/1983-80422018261224

9. Landesman P, diretor. Um homem entre gigantes [Concussion] [longa-metragem]. Culver City: Sony Pictures; 2015. 123min., som, cor.

10. Minayo MCS. Análise qualitativa: teoria, passos e fidedignidade. Ciênc Saúde Coletiva [Internet]. 2012 [acesso $1^{\circ}$ jul 2020];17(3):621-6. DOI: 10.1590/S1413-81232012000300007

11. Brown B. O poder da vulnerabilidade [podcast]. TED [Internet]. 2010 [acesso 3 maio 2019]. Disponível: https://bit.ly/38P9Wqj

12. Rebustini F, Machado AA. Modelo hierárquico de vulnerabilidade no esporte. Pensar Prát [Internet]. 2016 [acesso $1^{\circ}$ jul 2020];19(4):939-52. DOI: 10.5216/rpp.v19i4.41209

13. Sandoval PX. 99\% dos ex-jogadores da NFL têm lesões cerebrais, revela estudo. El País [Internet]. Esportes; 25 jul 2017 [acesso 3 maio 2019]. Disponível: https://bit.ly/3cljgxc

14. Bardin L. Análise de conteúdo. Lisboa: Edições 70; 2009.

15. Benites LC, Nascimento JV, Milistetd M, Farias GO. Análise de conteúdo na investigação pedagógica em educação física: estudo sobre estágio curricular supervisionado. Movimento [Internet]. 2016 [acesso $1^{\circ}$ jul 2020];22(1):35-50. DOI: 10.22456/1982-8918.53390

16. Rebustini F, Machado AA. Op. cit. p. 945.

17. Rebustini F, Machado AA. Op. cit. p. 946.

18. Organização das Nações Unidas para a Educação, a Ciência e a Cultura. Declaração universal sobre bioética e direitos humanos [Internet]. Paris: Unesco; 2006 [acesso $1^{\circ} \mathrm{dez} 2020$ ]. Disponível: https://bit.ly/36nCiXn

19. Goffman E. Estigma: notas sobre a manipulação da identidade deteriorada. Rio de Janeiro: Zahar; 1980.

20. Godoi AMM, Garrafa V. Leitura bioética do princípio de não discriminação e não estigmatização. Saúde Soc [Internet]. 2014 [acesso 4 dez 2020];23(1):157-66. DOI: 10.1590/S0104-12902014000100012

21. Kottow MH. Comentários sobre bioética, vulnerabilidade e proteção. In: Garrafa V, Pessini L, organizadores. Bioética: poder e injustiça. $2^{\text {a }}$ ed. São Paulo: Loyola; 2004. p. 73-8.

22. Leal LA. Análise do doping genético nos esportes e seu aspecto bioético. Rev Interdisciplin Ciênc Saúde [Internet]. 2017 [acesso $1^{\circ}$ jul 2020];4(2):71-80. Disponível: https://bit.ly/3pHRvKs

23. Silva TT. Questões éticas na prática da medicina do esporte na contemporaneidade. Rev. bioét. (Impr.) [Internet]. 2019 [acesso $1^{\circ}$ jul 2020];27(1):62-6. DOI: 10.1590/1983-80422019271287

24. Santos ALP, Simões AC. Educação física e qualidade de vida: reflexões e perspectivas. Saúde Soc [Internet]. 2012 [acesso $1^{\circ}$ jul 2020];21(1):181-92. DOI: 10.1590/S0104-12902012000100018

25. Benatar SR. Bioética: poder e injustiça. In: Garrafa V, Pessini L, organizadores. Bioética: poder e injustiça. $2^{a}$ ed. São Paulo: Loyola; 2004. p. 25-33.

26. Santin S. Educação física e desportos: uma abordagem filosófica da corporeidade. Rev Kines [Internet]. 1984 [acesso $1^{\circ}$ jul 2020]; (n esp):143-56. DOI: 10.5902/2316546410359 
Luciana Teixeira Waltrick - Mestre - lu.twaltrick@gmail.com

(D) 0000-0002-1425-0946

Francine Stein - Mestre - francinestein@unidavi.edu.br

(iD) 0000-0001-6501-0259

Alcyane Marinho - Doutora - alcyane.marinho@hotmail.com

(ID) 0000-0002-2313-4031

Correspondência

Luciana Teixeira Waltrick - Universidade do Estado de Santa Catarina.

Rua Doutor Abel Capella, 368, apt. 15, Coqueiros CEP 88080-250. Florianópolis/SC, Brasil.

Participação dos autores

Luciana Teixeira Waltrick delimitou o tema, coletou e, com Francine Stein, analisou os dados. Alcyane Marinho delimitou o tema e fez a revisão crítica do conteúdo em todas as fases da pesquisa. Todas as autoras contribuíram para a redação do artigo.

Recebido: $1^{\circ} .12 .2019$

Revisado: $\quad 3.12 .2020$

Aprovado: 12.12 .2020 